\title{
Presentation of pulmonary tuberculosis and actinomyces co-infection as a lung mass: a literature review and unique case report
}

\author{
Evangelos Balis ${ }^{1}$, Sotirios Kakavas ${ }^{1}$, Steven Kompogiorgas ${ }^{1}$, Konstantinos Kotsifas ${ }^{1}$, Georgios Boulbasakos ${ }^{1}$ \\ First Pulmonary Department, Evangelismos General Hospital of Athens, Greece
}

\begin{abstract}
Parenchymal lung infections occasionally present with clinical symptoms and radiological findings similar to lung malignancy. Pulmonary actinomycosis is a rare condition of its own right, let alone in coexistence with tuberculosis. We report a case of a man presenting with hemoptysis alongside a chest computed tomography compatible with lung cancer. The diagnosis, after removal of a large endobronchial mass with flexible bronchoscopy and cryon, was a concomitant infection with Mycobacterium tuberculosis and Actinomyces odontoliticus. In the literature, there are few reported cases with concomitant tuberculosis and actinomycosis. To our knowledge, such radical treatment without surgical intervention has not been reported in the past.
\end{abstract}

\section{Introduction}

Lung infections mimicking malignancy is an uncommon presentation. Thoracic actinomycosis can masquerade as primary

Correspondence: Steven Kompogiorgas, 1st Pulmonary Department, Evangelismos General Hospital of Athens, Ipsilantou 45-47, 10676, Athens, Greece.

Tel. +30.213.2041631 - Fax: +30.210 .7232370 .

E-mail: stevenkompogiorgas@googlemail.com

Key words: Interventional bronchoscopy; actinomycosis;

Mycobacterium tuberculosis; lung mass.

Contributions: All authors have read and approved of the manuscript, having contributed equally to the care of the patient, literature search, the writing of the manuscript, and preparation of the final document.

Conflict of interest: The authors declare that they have no conflict of interest or financial ties to disclose.

Received for publication: 5 October 2019.

Accepted for publication: 18 October 2019.

${ }^{\circ}$ Copyright: the Author(s), 2019

Licensee PAGEPress, Italy

Monaldi Archives for Chest Disease 2019; 89:1180

doi: 10.4081/monaldi.2019.1180

This article is distributed under the terms of the Creative Commons Attribution Noncommercial License (by-nc 4.0) which permits any noncommercial use, distribution, and reproduction in any medium, provided the original author(s) and source are credited. or metastatic lung cancer and in some cases, infection and cancer may even coexist. Actinomycosis occurs in humans worldwide and is usually caused by Actinomyces israelii, an anaerobic or microaerophilic, non-spore-forming, gram-positive rod. The extension of the infection in large bronchi is a rare manifestation of the disease. Most infections with Actinomyces spp. are polymicrobial [1]. However, cases with concomitant actinomycosis and tuberculosis appear to be rare. We present a case of a Mycobacterium tuberculosis co-infection with actinomycosis that presented as a large endobronchial mass. Written consent was obtained from the patient whose personal data were fully anonymized to protect the identity of the individual. This meets the requirements by the Ethics Committee of Evaggelismos General Hospital that approved the present case report. This case report aims to describe a case of co-infection of A. odontoliticus and $M$. tuberculosis presenting as an endobronchial mass in the greater context of the published literature, as well as highlight the challenges inherent in the diagnosis and management of this particular co-infection.

\section{Case Report}

A 62-year-old Caucasian male presented with a 20 days history of low grade fever, night sweats, shortness of breath, productive cough with blood-tinged sputum and weakness. He was a carpenter by occupation and an ex-smoker. His medical history revealed a previous pulmonary tuberculosis infection when he was 17 years old that was inappropriately treated. Additionally, the patient's history included bronchiectasis and chronic obstructive pulmonary disease (COPD) over the last 10 years that has been well controlled with combined inhalation therapy of corticosteroids and long acting beta-receptor agonists. He was also allergic to penicillin and clindamycin. There was neither travel history nor exposure to animals and no alcohol use.

Ten days prior to admission, he had been examined for the same symptoms by his family doctor and following a chest X-ray he received clarithromycin for community acquired pneumonia. The symptoms did not resolve and he was referred to our hospital. Physical examination upon admission, revealed blood pressure $130 / 85 \mathrm{mmHg}$, heart rate $90 / \mathrm{min}$, respiratory rate $20 / \mathrm{min}$ and body temperature $37.6^{\circ} \mathrm{C}$. In addition, lung auscultation was pathological with crackles over the lower lobes bilaterally, diminishing vesicular breath sound over the right middle lobe (RML) and wheezing. Arterial blood gases did not reveal respiratory failure $(\mathrm{pH} 7.39$, $\mathrm{PaO}_{2} 78 \mathrm{mmHg}, \mathrm{PaCO}_{2} 38 \mathrm{mmHg}$ ). Initial abnormal laboratory parameters included platelet count of $502,000 / \mu 1$ and $\mathrm{C}$-reactive protein $1.1 \mathrm{mg} / \mathrm{dl}$. Extensive laboratory tests for HIV, HBV, HCV and malignancy were negative. Computed tomography (CT) of the 
thorax revealed a well-defined mass in the middle lobe extending to the right lower lobe with surrounding airspace disease (Figure 1 A,B).

The patient underwent flexible fiberoptic bronchoscopy. A pale, polypoid and dense lesion was noted in the proximal portion of the right lower lobe bronchus. The lesion obstructed approximately $80 \%$ of the bronchial lumen also causing obstruction of the orifice of the right middle lobe due to pressure (Figure 2). Diffuse bleeding from the hypertrophic mucosa, purulent secretions and significant bronchomalacia were also noted. As the lesion was quite hard and we could not get large chunks for biopsy, we used cryoadhesion with a cryoprobe, and eventually we removed more than $70 \%$ of the lesion.

Histologically, the biopsy specimens were negative for cancer and Grocott-Gomori methenamine-silver nitrate stain revealed aggregates of Gram positive filamentous, branching bacteria with the characteristic "sulphur granules" of Actinomyces spp (Figure 3). The organism was initially identified by the hospital laboratory as Actinomyces spp and was then sent to a reference laboratory for definitive identification. The DNA of the isolate was subjected to 16S rRNA gene sequencing via PCR and the isolate was finally identified as $A$. odontoliticus. In addition, bronchoalveolar lavage culture for M. tuberculosis was positive. A diagnosis of bronchial actinomycosis concomitant with tuberculosis was made and therapy with INH - RIF - ETB - PZA for 8 weeks following INH - RIF for 18 weeks and doxycycline $200 \mathrm{mg}$ per day for 12 months was started. After 2 months of antituberculous therapy and oral doxycycline, the patient underwent a repeat $\mathrm{CT}$ that showed a significant resolution of all lesions in the lung (Figure 1C). At that time, the repeat bronchoscopy revealed minor residual disease at

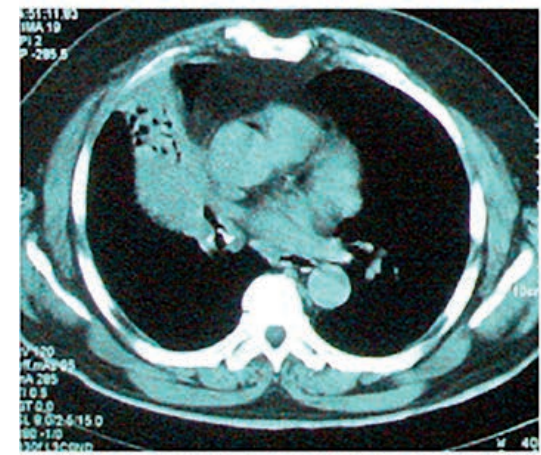

A

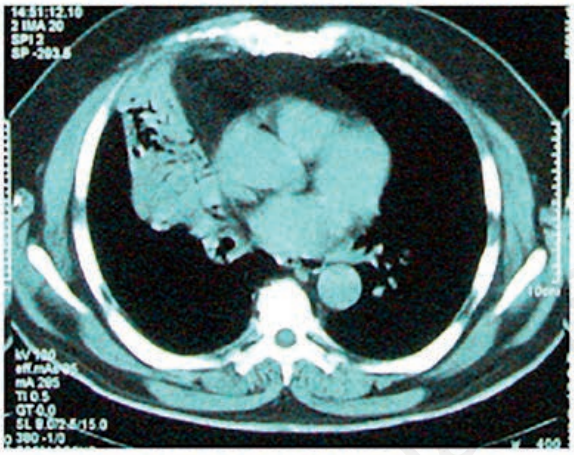

B

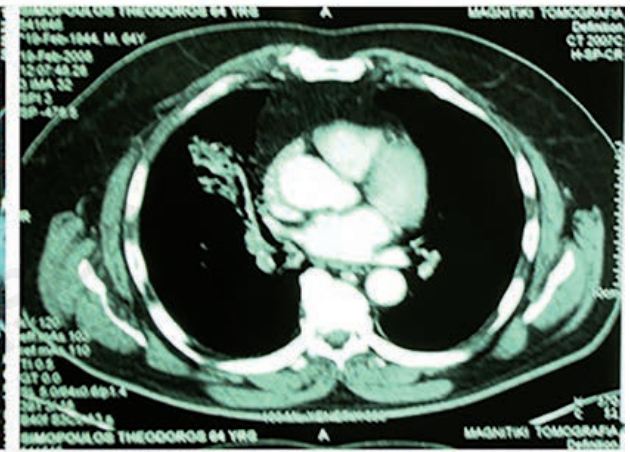

C

Figure 1. CT scans of the thorax. A,B) On admission, showing a right-middle-lobe lesion with surrounding airspace disease. C) Substantial resolution of the pulmonary lesion after 2 months of combined antibacterial and antituberculous therapy.

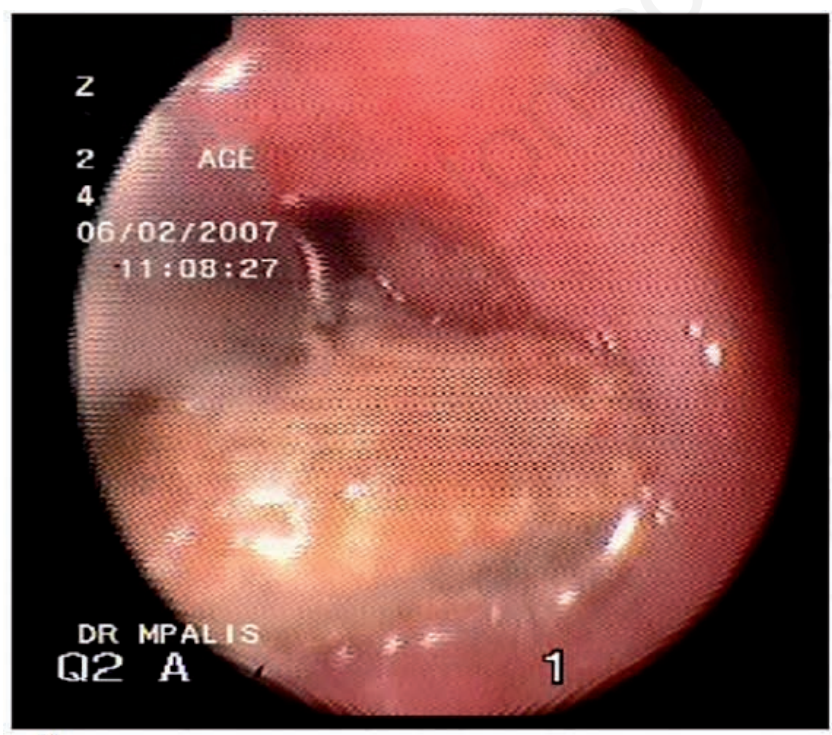

A

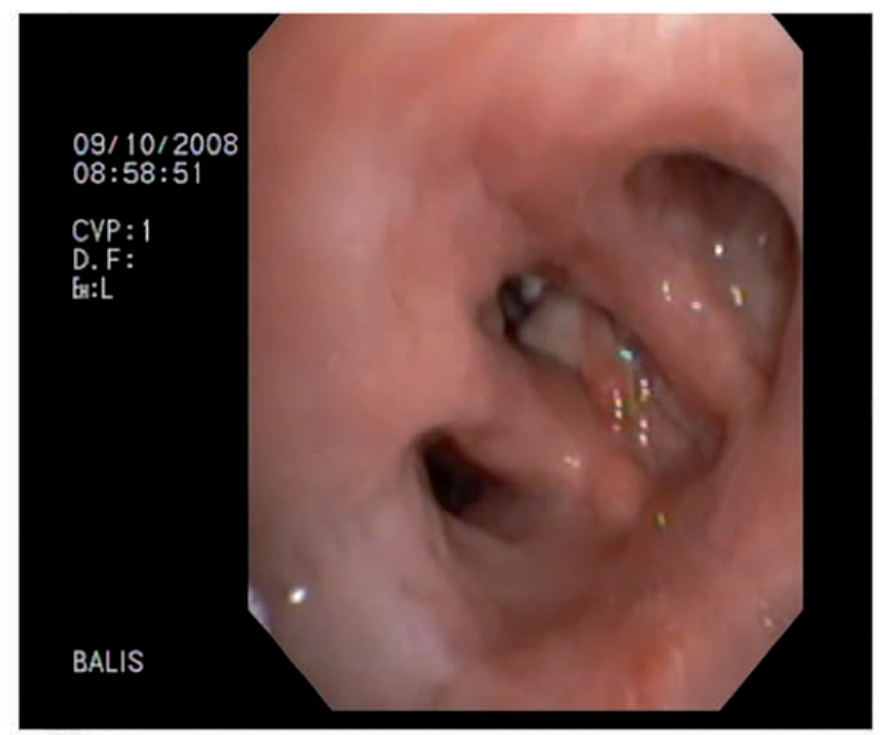

B

Figure 2. Bronchoscopic views. A) On admission, showing polypoid lesion in the proximal portion of the right lower lobe bronchus also causing obstruction of the orifice of the right middle lobe. B) Minor residual disease at the entrance of the lateral basal bronchus after 2 months of combined antibacterial and antituberculous therapy. 
the entrance of the lateral basal bronchus (Figure 2B). The bronchus was completely opened by the use of cryoadhesion with cryoprobe. Continuous follow up of the patient for 3 years showed no signs of recurrence of the disease.

\section{Discussion}

Actinomycosis is an infectious disease caused by filamentous, gram-positive, non-acid-fast, anaerobic-to-microaerophilic bacteria. Except $A$. israelii, which is the most common pathogen in humans, there are several other pathogens such as $A$. naesludii, $A$. odontoliticus, A. meyeri, A. gerencseriae and A. graevenitzi, which are less common causes of actinomycosis [2,3]. The most common clinical forms of actinomycosis are cervicofacial (40-60\%), thoracic (10-20\%), and abdominal/pelvic (20-30\%) [2,3]

Pulmonary actinomycosis is a rare disease and is often clinically confused with other pulmonary diseases like malignancy and chronic infections because commonly presents like pulmonary mass or infiltrate. The main problem is to differentiate the disease from lung cancer. The presence of an air bronchogram within a mass lesion in a chest CT should suggest the possibility of a nonneoplastic process. Other pulmonary findings in chest CT have been described including multiple nodular appearances, cavitations, pleural thickening, pleural effusions and hilar or mediastinal lymphadenopathy $[2,3]$.

In the literature there is no clear explanation for the predisposing factors and the role of immune system in actinomycosis. A pivotal step in the pathogenesis of actinomycosis is the disruption of the mucosal barrier so patients with poor dental hygiene, facial trauma, oral surgery, head and neck radiotherapy are in increased danger [1]. Pulmonary actinomycosis is mainly acquired through aspiration of the organism from the oropharynx; however the infection can also occur via inhalation, haematogenous dissemination and direct extension from adjacent tissues. Most importantly, actinomycosis is generally a polymicrobial infection, with isolates numbering

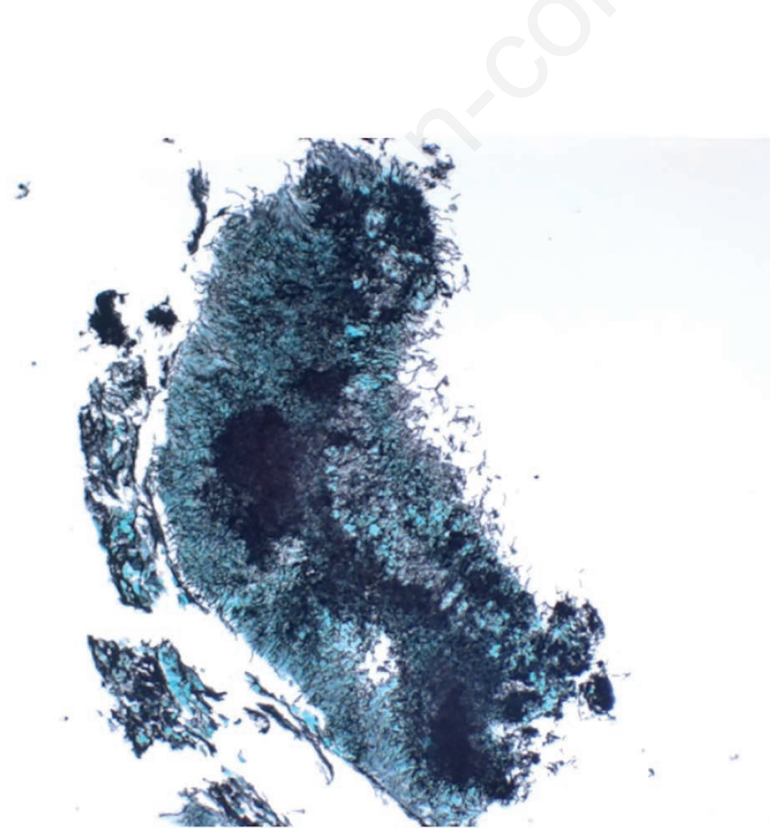

Figure 3. Grocott-Gomori methenamine-silver nitrate stain showing filamentous, branching aggregates and characteristic "sulphur granules" of Actinomyces spp. anywhere from two to four, and sometimes up to 10 bacterial species [1]. Co-infection may inhibit host defence mechanisms and/or reduce oxygen tension in the affected tissue, which enhances growth of Actinomyces spp. Co-pathogens commonly reported in pulmonary actinomycosis include Actinobacillus actinomycetemcomitans, Streptococcus spp., and Haemophilus spp. [1].

Interestingly, M. tuberculosis does not seem to be major cofactor in actinomycosis, although in 1950, Holm reported that actinomycosis co-infection with $M$. tuberculosis was "rarely encountered" in a series of 960 clinical isolates [4]. However, more recently Actinomyces have been found to participate in the sputum and lung microbiota of patients with tuberculosis [5,6]. A search in MEDLINE and EMBASE databases was carried out using the search terms "Actinomyces" or "actinomycosis" combined with the term "tuberculosis." Our electronic literature search located only eleven references as relevant with concomitant respiratory infection by $M$. tuberculosis and actinomycosis [7-17]. Of these, only 7 studies including 9 cases were available for review [7-13]. These cases are summarized in Table 1.

As in our case, most of the patients in previously reported cases presented with fever and pulmonary complaints, and diagnosis was made based on various isolates recovered from the respiratory system. However, only our patient presented with actinomycotic and tuberculous co-infection that included endobronchial actinomycosis. It should be noted that, between cases with reported species information, the majority of the isolates were $A$. israelii and only one case concerned $A$. graevenitzii. Therefore, to our knowledge the present case consists the first report of concomitant respiratory infection $M$. tuberculosis and A. odontolyticus. Furthermore, all previous cases have been treated with antibiotics with or without surgical intervention as needed. In our case, not only diagnosis but also treatment was assisted bronchoscopically along with the appropriate antibiotic treatment. Initial flexible bronchoscopy served the removal of the large endobronchial mass by the use of cryon, while repeat sessions assured the remission of the disease and the bronchial patency.

The rarity of the reported cases of actinomycotic and tuberculous co-infection has been attributed to various reasons. Firstly, concomitant actinomycotic infections may be underdiagnosed or underreported since it does not necessarily signify clinical disease. Secondly, the process of aerobic culture will negatively select most Actinomyces spp. [8]. Thirdly, clinically important Actinomyces species are not always identified because the differentiation process is laborious and expensive, while commercial identification kits may not include recently discovered Actinomyces species. Finally, it has been proposed that Actinomyces species are "incompatible" with tuberculous co-infection because they possess bacterial properties that hinder the growth of $M$. tuberculosis [18].

The endoscopic appearance of endobronchial actinomycosis can range from an irregularly raised mucosa or swelling to a mass that causes partial or complete occlusion of a bronchus [19]. An important point in endobronchial actinomycosis is the clinical appearance which resembles other endobronchial pathologies. In many cases non-specific symptoms such as cough, fever and recurrent pneumonias have been commonly reported. The above clinical symptoms in conjunction with a chest radiograph that resemble a spectrum from benign infection to malignancy make the diagnosis between malignancy, lung abscess and tuberculosis difficult and challenging. In general, bronchoscopy may not be diagnostic in every case of pulmonary actinomycosis [20] However, it should be performed as part of the differential diagnosis that also includes neoplasms or infections with similar radiological 
Table 1. Summary of previously reported cases of Actinomyces co-infection with M. tuberculosis.

\begin{tabular}{|c|c|c|c|c|c|c|c|}
\hline & Age (yr) & Ethnicity & Comorbidity & Thoracic lesion & $\begin{array}{l}\text { Actinomyces } \\
\text { species }\end{array}$ & Treatment & Outcome \\
\hline Bisero et al. (2016) & 13 & Caucasian & None & $\begin{array}{c}\text { Pneumonia, } \\
\text { thoracic wall abscess }\end{array}$ & Unknown & Penicillin, RHZE & Recovery \\
\hline Tietz et al. (2005) & 43 & $\begin{array}{l}\text { African-American } \\
\text { di }\end{array}$ & $\begin{array}{l}\text { Coronary artery } \\
\text { ease, hypertension }\end{array}$ & Pneumonia, cavity & A. graevenitzii & Amoxicillin, RHZE & Recovery \\
\hline Stein et al. (1983) & 12 & African-American & None & $\begin{array}{c}\text { Cavity, } \\
\text { thoracic wall abscess }\end{array}$ & A. israelii & Penicillin, RHE & Recovery \\
\hline $\begin{array}{l}\text { Chakravarty and } \\
\text { Fernandez (1977) } \\
\text { (patient \#1) }\end{array}$ & 22 & Asian Indian & None & Cavity & A. israelii & Penicillin, HS, PAS & Recovery \\
\hline $\begin{array}{l}\text { Chakravarty and } \\
\text { Fernandez (1977) } \\
\text { (patient \#2) }\end{array}$ & 30 & Asian Indian & None & Bilateral cavities & A. israelii & Penicillin, HS & Recovery \\
\hline Lee (1966) & 35 & African-American & None & Cavity, pleural empyema & Unknown & $\begin{array}{c}\text { Penicillin, } \\
\text { unknown tuberculosis } \\
\text { treatment, } \\
\text { lung resection }\end{array}$ & Recovery \\
\hline $\begin{array}{l}\text { Bates and } \\
\text { Cruickshank (1957) } \\
\text { (patient \#1) }\end{array}$ & Unknown & Caucasian & Unknown & Empyema & A. israelii & $\begin{array}{l}\text { Unknown antibiotics, } \\
\text { thoracoplasty }\end{array}$ & Recovery \\
\hline $\begin{array}{l}\text { Bates and } \\
\text { Cruickshank (1957) } \\
\text { (patient \#2) }\end{array}$ & Unknown & Caucasian & Unknown & Empyema & A. israelii & $\begin{array}{l}\text { Unknown antibiotics, } \\
\text { thoracoplasty }\end{array}$ & $\begin{array}{l}\text { Death from } \\
\text { amyloidosis }\end{array}$ \\
\hline von Arnim (1949) & 42 & Caucasian & None & Cavity, substernal abscess & Unknown & $\begin{array}{l}\text { Neoarsephenamine, } \\
\text { Sulphonamides, } \\
\text { incision and drainage } \\
\text { of abscesses }\end{array}$ & $\begin{array}{c}\text { Death from } \\
\text { pulmonary } \\
\text { haemorrhage }\end{array}$ \\
\hline
\end{tabular}

R, rifampin; H, isoniazid; Z, pyrazinamide; E, ethambutol; S, streptomycin; PAS, para-aminosalicylic acid.

or clinical characteristics. Especially in the case of endobronchial actinomycosis, the diagnostic capacity of flexible bronchoscopy increases substantially. In this clinical setting bronchoscopy may also provide a window of opportunity to completely remove the endobronchial mass or at least decrease the burden of the disease while acting as a therapeutic adjunct. Nevertheless, co-infection of M. tuberculosis and Actinomyces spp. represents a rare, but difficult challenge in clinical practice. This highlights the importance of timely diagnosis and treatment to avoid interventions requiring considerable time, effort and risk to the patient.

\section{References}

1. Russo TA. Agents of actinomycosis. In: Mantel GL, Bennett JE, Dolin R, Editors. Principals and practices of infectious diseases. Philadelphia; Churchill Livingstone, 2005; pp. 2924-34.

2. Schaal KP, Lee HJ. Actinomycete infections in humans-a review. Gene 1992;115:201-11.

3. Boyanova L, Kolarov R, Mateva L, et al. Actinomycosis: a frequently forgotten disease. Future Microbiol 2015;10:613-28.

4. Holm P. Studies on aetiology of human actinomycosis. Acta Pathol Microbiol Scand 1950;27:736-51.

5. Hong BY, Paulson JN, Stine OC, et al. Meta-analysis of the lung microbiota in pulmonary tuberculosis. Tuberculosis (Edinb). 2018;109:102-8.

6. Cheung MK, Lam WY, Fung WY, et al. Sputum microbiota in tuberculosis as revealed by $16 \mathrm{~S}$ rRNA pyrosequencing. PLoS One 2013;8:1-8.

7. Bisero ED, Luque GF, Rizzo CN, et al. Pulmonary actinomycosis and tuberculosis. A comorbidity pediatric case. Arch Argent Pediatr 2016;114:233-6.

8. Tietz A, Aldridge KE, Figueroa JE. Disseminated coinfection with Actinomyces graevenitzii and Mycobacterium tuberculosis: case report and review of the literature. J Clin Microbiol 2005;43:3017-22.

9. Stein CA, Ernst J, Stern M, et al. Thoracic actinomycosis in a recent tuberculin converter. Pediatr Infect Dis 1983;2:52-5.

10. Chakravarty SC, Fernandez J. Co-existence of actinomycosis of lungs with pulmonary tuberculosis. J Indian Med Assoc 1977;69:89-90.

11. Lee BY. Actinomycosis of the lung coexisting with pulmonary tuberculosis. Report of a case. Dis Chest 1966;50:211-3.

12. Bates M, Cruickshank G. Thoracic actinomycosis. Thorax 1957;12:99-124.

13. von Arnim HH. [On a case of simultaneous thoracic actinomycosis and tuberculosis of the lung].[Article in German]. Beitr Klin Tuberk Spezif Tuberkuloseforsch 1949;101:595-607.

14. Goldshtein VD, Mirinov GB. [On the combination of tuberculosis of the lungs and actinomycosis].[Article in Russian]. Klin Med (Mosk) 1962;40:107-10.

15. Gondzik, M, Jasiewicz Z. [Case of pulmonary tuberculosis complicated by actinomycosis of the paravesical region].[Article in Polish]. Wiad Lek 1975;28:1869-71.

16. Krakowka, P, Traczyk K, Ginterowa B. [A case of co-existing 
pulmonary tuberculosis and primary actinomycosis].[Article in Polish]. Gruzlica 1962;30:1095-100.

17. Morozova OV, Girshov BD, Barkan IL. [Tuberculosis actinomycosis and candidiasis in a patient with diabetes mellitus].[Article in Russian]. Klin Med (Mosk) 1966;44:122-4.

18. Nikiforchin RN. [Antagonistic properties of actinomyces isolated from patients with fibrous-cavernous pulmonary tuberculosis].[Article in Russian]. Probl Tuberk 1968;46:61-5.

19. Dalhoff K, Wallner S, Finck C, et al. Endobronchial actinomycosis. Eur Respir J 1994;7:1189-91.

20. Jensen BM, Kruse-Andersen S, Andersen K. Thoracic actinomycosis. Scand J Thorac Cardiovasc Surg 1989; 23:181-4 